\title{
Eveningness is associated with higher risk-taking in dangerous driving situations
}

\author{
Natalia Rusnac, Florence Spitzenstetter, and Patricia Tassi \\ Faculty of Psychology, University of Strasbourg, Strasbourg, France
}

\begin{abstract}
Inclination toward eveningness is often associated with risky behavior. But the existing studies are scarce, inconsistent and usually limited to self-reported measures. We sought to investigate in young adults whether morningness-eveningness is associated with risky behavior in dangerous driving situations, with self-reported drunk driving and with alcohol consumption. Results show that, indeed, inclination toward eveningness is associated with these risky behaviors. We also demonstrate a link between morningness-eveningness and sensation seeking. Therefore, young adults with a tendency toward eveningness might be more at risk to face negative consequences of alcohol abuse or to be involved in a road accident.
\end{abstract}

KEYWORDS

Alcohol consumption; drunk driving; morningness-eveningness; risky driving behavior; sensation seeking

\section{Introduction}

Chronotype, or morningness-eveningness preference, has been consistently linked to physical health (Merikanto et al., 2013; Osonoi et al., 2014), mental health (Drennan et al., 1991; Wood et al., 2009), personality traits (Caci et al., 2005; Tonetti et al., 2010), self-control (Digdon \& Howell, 2008; Milfont \& Schwarzenthal, 2014), etc. More recently, a growing body of research has shown that morningness-eveningness is associated with risk-taking behavior (Killgore, 2007; Ponzi et al., 2014; Wang \& Chartrand, 2015).

Morningness-eveningness refers to individual differences in terms of circadian rhythms preference. According to Natale and Cicogna (2002), morningness-eveningness can be seen as a continuum along two extremes. One extreme is represented by morning-type individuals (also called "larks") who prefer to wake up and to go to bed early and have their peak cognitive and physical performance in the morning. At the other extreme of the continuum are situated evening-type individuals (also described as "owls"), who prefer to wake up and go to bed late and perform best in the afternoon or in the evening. Most people (60$70 \%$ ) however have an intermediate chronotype, in other words they fall between these two extremes.
Research shows that evening-type individuals have risk-related personality traits (Caci et al., 2004; Tonetti et al., 2010) and a higher propensity for risky behavior (Killgore, 2007; Ponzi et al., 2014; Wang \& Chartrand, 2015). Most studies investigating the link between morningness-eveningness and risk are based on measures of self-reported propensity to take risks. For example, Killgore (2007) found that inclination toward eveningness is indeed associated with a higher self-reported propensity to adopt risky behavior. Wang and Chartrand (2015) studied this link in five specific domains (ethical, financial, health/safety, recreational and social) using the Domain-Specific Risk-Taking Scale (DOSPERT). An association between eveningness and self-reported propensity to adopt risky behaviors was found, but only in the financial domain (e.g. gambling, investment). Using the same scale, Ponzi et al. (2014) however found that eveningness was associated with a greater propensity to take risks in three out of five domains, specifically the financial, ethical and recreational domains. This literature suggests that the link between chronotype and risky behavior is not consistent across different domains and across studies.

Another issue of the existing research is that it often relies on self-reported measures of the propensity for risk-taking. These are subjective 

assessments and therefore they do not always reflect objective risk-taking behavior. For this reason, using a behavioral measure could be more appropriate. To date, very few studies investigating the link between morningness-eveningness and risk have used behavioral measures of risk-taking and the results are again inconsistent. Killgore (2007) found that morningness-eveningness scores were not correlated with the scores obtained at the Balloon Analog Risk Task (BART) designed to measure risk-taking in terms of monetary gains. Wang and Chartrand (2015) used a scenario-based risky behavior measurement and found that eveningness was associated with higher risk-taking in terms of investment and gambling, but not in terms of health. Therefore, not only the existing data on the relationship between morningnesseveningness and risk-taking behavior are scarce and inconsistent, but when a link is found it concerns only some specific domains of risk-taking.

No research so far has investigated whether morningness-eveningness is associated with risky behavior in the context of driving. Therefore, the aim of the present study was to investigate the link between morningness-eveningness and risky driving behavior among young adults. Since selfreported propensity for risk-taking does not always reflect behavioral measures of risk-taking, we used a behavioral measure applied in a setting close to real-life driving situations. Specifically, we used the Vienna Risk Taking Test, which assesses risk-taking behavior in 24 different driving situations (Hergovich et al., 2007). We also measured self-reported drunk driving behavior and selfreported alcohol consumption. We hypothesized that propensity toward eveningness would be associated with higher risk-taking in dangerous driving situations, greater alcohol use and more frequent drunk driving.

In addition, given that several studies demonstrate the link between morningness-eveningness and personality traits related to risk, we thought it interesting to measure sensation seeking, which is considered to be one of the personality traits most strongly associated with risky behavior (Zuckerman et al., 1964; Zuckerman, 1994). To date, only two studies have investigated this link, both of them showing that evening-type individuals have a higher propensity for sensation seeking (Killgore, 2007; Tonetti et al., 2010). We expect to replicate these findings in our study.

\section{Materials and methods}

\section{Participants and procedure}

A total of 188 university students ranging from 19 to 25 years old $(\mathrm{M}=22.35$ years, $\mathrm{SD}=1.47,50.5 \%$ women) participated in this research. Only subjects who reported sleeping enough and being satisfied with their sleep were selected in this study. The average sleep duration in our sample was 7.7 hours $(S D=.70)$ per night.

All the participants have had their driving license for at least 2 years. This research was approved by the Ethical Committee of the Faculty of Psychology of the University. Participants provided their informed consent prior to taking part in the study and were paid for their participation. The study was conducted throughout the entire day, between 9 am and $5 \mathrm{pm}$.

\section{Measures}

Morningness-eveningness was measured using the French version of the Morningness-Eveningness Questionnaire (MEQ; Horne \& Ostberg, 1976), which consists of 19 multiple-choice questions.

To assess risk-taking behavior in virtual driving situations, we used the Vienna Risk-Taking Test Traffic (Hergovich et al., 2007). Participants were presented with 24 brief videos of potentially dangerous traffic situations. The videos were filmed from inside the car, so that the participant could easily picture himself as the driver of the car. Each video was watched twice. The first time, participants were asked to simply observe what was happening in the video. The second time, they had to press a key to indicate at which point they would no longer carry out a particular driving maneuver because they considered that it was too dangerous. The longer participants waited before pressing the response key, the higher was the risk they took. Response latencies (ms) were measured for each of the 24 driving situations.

We also asked participants to complete the Sensation Seeking Scale (Carton et al., 1990; Zuckerman, 1994; Zuckerman et al., 1964) that 
consisted of 72 forced-choice questions with two possible answers. In addition, participants reported their usual alcohol consumption in terms of frequency (they were asked how often they drank alcohol on a 6-point scale ranging from "never" (1) to "every day" (6)) and quantity (they reported the mean number of drinks they had per week). To measure self-reported drunk driving behavior, participants were asked to indicate on a 6-point scale ranging from "never" (1) to "always" (6) how often they took the wheel after drinking.

\section{Data analyses}

A morningness-eveningness score per participant was computed by adding together the responses to the 19 questions of the MEQ, with higher scores indicating greater preference toward morningness. In the present study, morningness-eveningness scores ranged from 26 to $79(\mathrm{M}=51.66, \mathrm{SD}=$ 8.80 ). To convert raw scores into categories, different approaches can be used. For example, the median split method (Bodenhausen, 1990; Killgore, 2007) or predetermined cutoff criteria (Horne \& Ostberg, 1976; Tonetti et al., 2010) can be applied. Using the cutoff criteria of the French version of the MEQ, subjects who scored above 70 were labeled as definitely morning types, while those having scores between 59 and 69 were considered moderately morning types. Scores ranging from 42 to 58 identified participants as intermediate types. Subjects with scores between 31 and 41 were categorized as moderately evening types, whereas those who scored below 30 were identified as definitely evening types. Using these criteria we identified in our sample four definitely morning types $(2.13 \%), 37$ moderately morning types (19.68\%), 122 intermediate types (64.89\%), 23 moderately evening types $(12.23 \%)$ and two definitely evening types $(1.06 \%)$.

However, as noted by Natale and Cicogna (2002), because evening and morning-type individuals are significantly fewer than intermediatetype individuals, data can be difficult to compare and interpret. Therefore, rather than work with discrete categories, we thought it more useful to consider morningness-eveningness as a continuum (Killgore, 2007; Natale \& Cicogna, 2002) and use the raw scores to conduct correlational analyses.

Regarding sensation seeking, we computed the general sensation-seeking factor score by adding together the answers to the 22 questions pertaining to general sensation seeking. Therefore, the sensation-seeking scores range from 0 to 22. Higher scores represent a higher propensity for sensation seeking.

As to the behavioral measure of risk-taking in driving situations, a mean score per participant was obtained, with higher latency scores indicating greater risk-taking.

\section{Results}

We performed correlational analyses between the main variables of the study: morningness-eveningness score, risky driving behavior, self-reported frequency and quantity of alcohol use, self-reported drunk driving and sensation seeking (cf. Table 1).

As shown in Table 1, the morningness-eveningness score is significantly correlated with risky driving behavior $(r=-.20, p<.01)$, indicating that the

Table 1. Correlation coefficients between the main variables of the study.

\begin{tabular}{|c|c|c|c|c|c|c|}
\hline & $\begin{array}{l}\text { Morningness- } \\
\text { eveningness score }\end{array}$ & $\begin{array}{c}\text { Risky driving } \\
\text { behavior }\end{array}$ & $\begin{array}{l}\text { Self-reported } \\
\text { drunk driving }\end{array}$ & $\begin{array}{c}\text { Self-reported alcohol } \\
\text { use (frequency) }\end{array}$ & $\begin{array}{c}\text { Self-reported alcohol } \\
\text { use (quantity) }\end{array}$ & $\begin{array}{r}\text { Sensation } \\
\text { seeking }\end{array}$ \\
\hline $\begin{array}{l}\text { Morningness- } \\
\text { eveningness score }\end{array}$ & - & - & - & - & - & - \\
\hline Risky driving behavior & $r=-.20^{* *}$ & - & - & - & - & - \\
\hline $\begin{array}{l}\text { Self-reported drunk } \\
\text { driving }\end{array}$ & $r=-.19^{* *}$ & $r=.14$ & - & - & - & - \\
\hline $\begin{array}{l}\text { Self-reported alcohol } \\
\text { use (frequency) Self- }\end{array}$ & $r=-.35^{* * *}$ & $r=.20^{* *}$ & $r=.41^{* * *}$ & - & - & - \\
\hline $\begin{array}{l}\text { reported alcohol } \\
\text { use (quantity) }\end{array}$ & $r=-.32^{* * *}$ & $r=.12$ & $r=.34^{* * *}$ & $r=.67^{* * *}$ & - & - \\
\hline Sensation seeking & $r=-.17^{*}$ & $r=.13$ & $r=.23^{* *}$ & $r=.27^{* * *}$ & $r=.20^{* *}$ & - \\
\hline
\end{tabular}


higher the tendency toward eveningness, the riskier the behavior in dangerous driving situations. There is also a negative correlation between the morningness-eveningness score and self-reported drunk driving behavior $(r=-.19, p<.01)$ : the more people have an inclination toward eveningness, the more likely they are to drive after drinking alcohol.

In addition, analyses reveal significant negative correlations between the morningness-eveningness score and self-reported alcohol consumption in terms of both frequency $(r=-.35, p<.001)$ and quantity $(r=-.32, p<.001)$, indicating that the more people have an inclination toward eveningness, the more alcohol they drink.

Finally, the morningness-eveningness score is also significantly correlated with sensation seeking $(r=-.17, p<.05)$, showing that participants with a greater tendency toward eveningness have higher sensation-seeking scores.

\section{Discussion}

This is the first study to investigate the link between morningness-eveningness and risky driving behavior and to show that inclination toward eveningness is associated with greater risk-taking in dangerous driving situations. In addition, a major strength of the present research is that risky driving behavior was assessed with a behavioral measure instead of a self-reported one. Another original result of the present study pertains to drunk driving behavior measured with a self-reported approach. We show that propensity toward eveningness is related to more frequent drunk driving. Therefore, our study makes an important contribution to the literature on the link between morningness-eveningness and risk.

Moreover, our results provide support for previous research showing a link between eveningness and risky behavior in domains other than driving, for example in the financial domain (Wang \& Chartrand, 2015). We also show that inclination toward eveningness is associated with more selfreported alcohol use in terms of quantity and frequency, which is consistent with prior research showing that alcohol consumption is more prevalent among evening-type individuals (Adan, 1994; Prat \& Adan, 2011; Wittmann et al., 2010).
Unsurprisingly, our results also indicate that propensity toward eveningness is associated with higher sensation seeking. This is in line with studies showing that evening-type individuals have higher sensation-seeking scores than morningtype individuals (Killgore, 2007; Tonetti et al., 2010). On a more general level, these results are consistent with research showing a link between eveningness and various other risk-related personality traits such as impulsivity (Adan et al., 2010; Caci et al., 2005; Killgore, 2007) and novelty seeking (Caci et al., 2004).

Our results highlight the critical role played by stable traits such as morningness-eveningness and personality traits (sensation seeking) in risky behaviors. From an evolutionary point of view, Ponzi et al. (2014) advance the idea that eveningness, sensation seeking and the propensity for risk-taking can be seen as a cluster of traits that might have evolved to improve survival and reproduction in stressful and unpredictable environments.

Due to its correlational nature, our study does not allow one to establish a causal relationship between preference for eveningness and risky behavior. Moreover, since some correlation values are moderate, speculations on this relationship must remain cautious at this stage.

The mechanisms underlying the association between propensity toward eveningness and risky behavior remain unclear. One explanation, as suggested by Tonetti et al. (2010), is based on social jet lag, i.e. a mismatch between social schedules and biological rhythms (Wittmann et al., 2006). Social jet lag, a common phenomenon among evening-type individuals, can cause sleepiness. Evening-type individuals could be more inclined to take risks because by increasing the level of arousal, risk-taking could help compensate the sleepiness caused by social jet lag. Wang and Chartrand (2015) suggest an additional explanation based on the possibility that evening-type individuals need to constantly meet external demands (e.g. early work hours) that are inconsistent with their circadian preference. Meeting such demands leads to exhaustion of self-control resources, which could result in more impulsive and risky behaviors. This explanation is however unlikely in the present study because our participants declared having 
sufficient sleep quantity and quality, unless fatigue was not subjectively experienced. Another explanation could refer to thinking styles. Risky behavior and alcohol consumption are often associated with a more creative and intuitive thinking style, which has been essentially described in evening types. Díaz-Morales and Escribano (2013) have recently confirmed in school children that evening types are usually "right-thinkers" who tend to be creative and intuitive, whereas morning types tend to be "left-thinkers" who prefer verbal and analytic strategies in information processing. Further research should be carried out to investigate these various hypotheses.

In conclusion, this is the first study to our knowledge to show that inclination toward eveningness is associated with risky driving behavior in dangerous traffic situations and with more frequent drunk driving. We also provide support for previous research by showing that preference for eveningness is associated with greater alcohol consumption and with higher sensation seeking. Taken together, our findings suggest that evening-oriented young adults are more likely to be affected by the negative consequences of alcohol abuse or to be involved in a traffic accident.

\section{Declaration of interest}

The present research was funded by the MAIF Foundation, France. The authors report no conflict of interest.

\section{References}

Adan A. (1994). Chronotype and personality factors in the daily consumption of alcohol and psychostimulants. Addiction. 89:455-62.

Adan A, Natale V, Caci H, Prat G. (2010). Relationship between circadian typology and functional and dysfunctional impulsivity. Chronobiol Int. 27:606-19.

Bodenhausen GV. (1990). Stereotypes as judgmental heuristics: Evidence of circadian variations in discrimination. Psychol Sci. 1:319-22.

Caci H, Mattei V, Baylé FJ, et al. (2005). Impulsivity but not venturesomeness is related to morningness. Psychiatry Res. 134:259-65.

Caci H, Robert P, Boyer P. (2004). Novelty seekers and impulsive subjects are low in morningness. Eur Psychiat. 19:79-84.

Carton S, Lacour C, Jouvent R, Widlocher D. (1990). Le concept de recherche de sensations: Traduction et validation de l'échelle de Zuckerman. Psychiatr Psychobiol. 5:39-48.
Díaz-Morales JF, Escribano C. (2013). Circadian preference and thinking styles: Implications for school achievement. Chronobiol Int. 30:1231-9.

Digdon NL, Howell AJ. (2008). College students who have an eveningness preference report lower self-control and greater procrastination. Chronobiol Int. 25:1029-46.

Drennan MD, Klauber MR, Kripke DF, Goyette LM. (1991). The effects of depression and age on the Horne-Ostberg morningness-eveningness score. J Affect Disord. 23:93-8.

Hergovich A, Arendasy ME, Sommer M, Bognar B. (2007). The vienna risk-taking test - Traffic. A new measure of road traffic risk-taking. J Individ Dif. 28:198-204.

Horne JA, Ostberg O. (1976). A self-assessment questionnaire to determine morningness-eveningness in human circadian rhythms. Int J Chronobiol. 4:97-110.

Killgore WDS. (2007). Effects of sleep deprivation and morningness-eveningness traits on risk-taking. Psychol Rep. 100:613-26.

Merikanto I, Lahti T, Puolijoki H, et al. (2013). Associations of chronotype and sleep with cardiovascular diseases and type 2 diabetes. Chronobiol Int. 30:470-7.

Milfont TL, Schwarzenthal M. (2014). Explaining why larks are future-oriented and owls are present-oriented: Selfcontrol mediates the chronotype-time perspective relationships. Chronobiol Int. 31:581-8.

Natale V, Cicogna P. (2002). Morningness-eveningness dimension: Is it really a continuum? Pers Indiv Differ. 32:809-16.

Osonoi Y, Mita T, Osonoi T, et al. (2014). Morningnesseveningness questionnaire score and metabolic parameters in patients with type 2 diabetes mellitus. Chronobiol Int. 31:1017-23.

Ponzi D, Wilson MC, Maestripieri D. (2014). Eveningness is associated with higher risk-taking, independent of sex and personality. Psychol Rep. 115:932-47.

Prat G, Adan A. (2011). Influence of circadian typology on drug consumption, hazardous alcohol use, and hangover symptoms. Chronobiol Int. 28:248-57.

Tonetti L, Adan A, Caci H, et al. (2010). Morningness-eveningness preference and sensation seeking. Eur Psychiat. 25:111-5.

Wang L, Chartrand TL. (2015). Morningness-eveningness and risk taking. J Psychol. 149:394-411.

Wittmann M, Dinich J, Merrow M, Roenneberg T. (2006). Social jetlag: Misalignment of biological and social time. Chronobiol Int. 23:497-509.

Wittmann M, Paulus M, Roenneberg T. (2010). Decreased psychological well-being in late 'chronotypes' is mediated by smoking and alcohol consumption. Subst Use Misuse. 45:15-30.

Wood J, Birmaher B, Axelson D, et al. (2009). Replicable differences in preferred circadian phase between bipolar disorder patients and control individuals. Psychiatry Res. 166:201-9.

Zuckerman M. (1994). Behavioral expressions and biosocial bases of sensation seeking. New York, NY: Cambridge University Press.

Zuckerman M, Kolin EA, Price L, Zoob I. (1964). Development of a sensation-seeking scale. J Consult Psychol. 28:477-82. 